\section{Destruction of toxic materials}

SIR - Increased awareness and understanding of the hazards to health and the environment of many synthetically produced chemicals have led to the need for development of a safe means for their effective disposal. Because of their high toxicity and persistence, halogenated organic compounds and other organochlorine pesticides such as DDT, PCBs, aryl halides and dioxins are of particular concern. Current methods of disposal ${ }^{1}$ involving high-temperature chemical reactions can be accompanied by unwanted toxic emissions or by-products, which may involve unacceptable risks to the environment. We have developed a low-temperature process ${ }^{2}$ involving mechanochemical reactions ${ }^{3}$ induced by mechanically milling the toxic material with a suitable reactant in a closed vessel. Such reactants may include reductants which break down the entire molecule or react selectively to remove chlorine. Laboratory measurements of the mechanochemical reaction of DDT, PCB and chlorobenzene with magnesium, calcium and calcium oxide show the destruction of the organochlorines without the formation of toxic by-products.

We milled individual samples of chlorinated organic compounds, including DDT, PCB (Aroclor 1254) and chlorobenzene with $\mathrm{Ca}, \mathrm{Mg}, \mathrm{Fe}$ or $\mathrm{CaO}$ as a reactant in a laboratory vibratory mill (SPEX 8000). Each test consisted of milling a total of 5-10 $\mathrm{g}$ organochlorine and the reactant using $12-\mathrm{mm}$ diameter steel balls in a sealed steel vial. The figure shows a total ion chromatogram (TIC) from gas chromatography-mass spectroscopy (GC-MS) of compounds present after milling a sample of DDT and $\mathrm{Mg}$ for 3 and $6.5 \mathrm{~h}$. Chlorinated break-up products and products of partial dechlorination of DDT were present after $3 \mathrm{~h}$ milling ( $a$ in the figure, retention time $t=10-30 \mathrm{~min}$ ). Partially dechlorinated oligomer-type materials of DDT ( $t=31-35 \mathrm{~min}$ ) were also present. The presence of chlorinated compounds was not evident from analysis of the TIC from GC-MS of the sample milled for $6.5 \mathrm{~h}(b, t=10-12 \mathrm{~min})$. We found very small quantities (low p.p.m.) of dechlorinated products, such as diphenylmethane and diphenylethanes (inset in $b$ ). These compounds were not present in the DDT used for milling, so must have formed during milling.

The levels of DDT and related compounds DDD (DDT minus $\mathrm{Cl}$ ) and DDE (DDT minus $\mathrm{HCl}$ ) and the levels of chlorobenzene and PCB determined by dual-column gas chromatographyelectron capture detection and expressed as the fraction in p.p.m. of the original organochlorine compounds remaining after being milled for 12 hours, are summa- rized in the table. For each reactant, the results for the three organochlorines were similar even though both the PCB and chlorobenzene were in liquid form whereas the DDT was solid. $\mathrm{Mg}, \mathrm{Ca}$ and $\mathrm{CaO}$ were all highly effective in dechlorinating the organochlorine reactants. When Fe was used, milling for $12 \mathrm{~h}$ resulted in incomplete dechlorination.

The importance of mechanochemical activation is that, with suitable choice of reactants, the reaction can occur at low temperatures in a sealed environment to form safe reaction products requiring onily minimal additional processing. Further, the process is based on well-established ball-milling technology and can be scaled
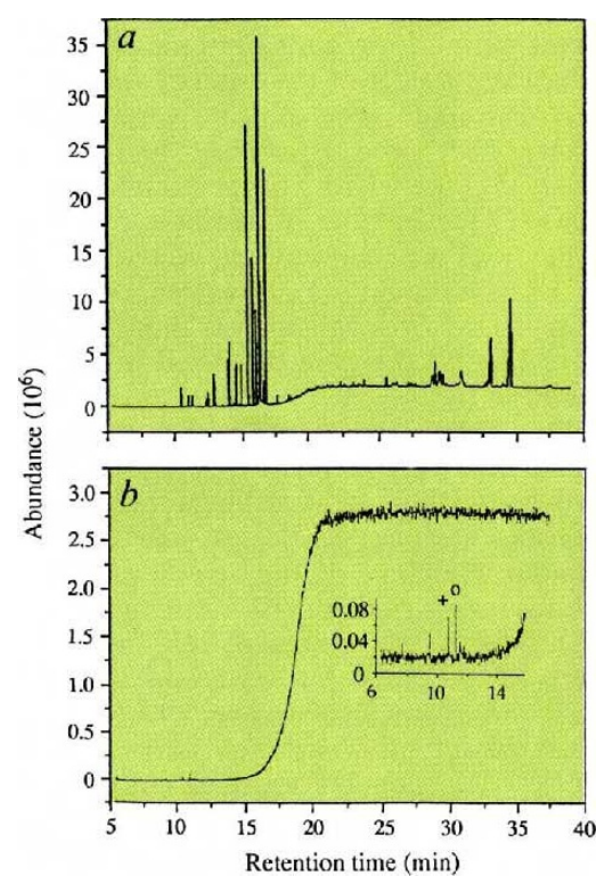

GC-MS chromatograms of samples of DDT milled with $\mathrm{Mg}$ : $a$, after $3 \mathrm{~h}$ milling; $b$, after $6.5 \mathrm{~h}$ milling. Cross, diphenylmethane; circle, diphenylethane. Measurements were carried out after extraction into $n$-pentane using a HP 5890 ॥ GC-MSD 5790 instrument fitted with a DB- 5 column of $30 \mathrm{~m}$ length, inside diameter $0.25 \mathrm{~mm}$ and film thickness $0.25 \mu \mathrm{m}$. The carrier gas was helium at $70 \mathrm{kPa}$. The temperature programme was $40^{\circ} \mathrm{C}$ for $2 \mathrm{~min}$, then $15^{\circ} \mathrm{C}$ per min to $310^{\circ} \mathrm{C}$ and held for $20 \mathrm{~min}$.

\begin{tabular}{cccc}
\hline \multicolumn{4}{c}{ MILLING EXPERIMENTS WITH } \\
VARIOUS REACTANTS \\
\hline \multicolumn{4}{c}{ Remaining } \\
organochlorine (p.p.m.) \\
Reactant & DDT & Chlorobenzene & PCB \\
$\mathrm{Mg}$ & 4 & $<1$ & 260 \\
$\mathrm{Ca}$ & $<1$ & 50 & 1,400 \\
$\mathrm{Fe}$ & 36,000 & 280 & 120,000 \\
$\mathrm{CaO}$ & 4 & 7 & 5 \\
\hline
\end{tabular}

Values under 'DDT' also refer to DDD and DDE. to any size. Mobile mills mounted on road or rail vehicles may be used for on-site processing, thus eliminating the environmental hazards associated with the transport of toxic materials. $\mathrm{CaO}$ would be the preferred reactant because it is cheap and the reaction products can be disposed of safely.

\section{S. A. Rowlands}

A. K. Hall

P. G. McCormick

Department of Mechanical and Materials

Engineering,

\section{R. Street}

\section{Department of Physics,}

University of Western Australia,

Nedlands, WA6009, Australia

\section{R. J. Hart}

\section{G. F. Ebell}

Environmental Chemist Laboratory,

Chemistry Centre of WA,

East Perth, WA 6004,

Australia

P. Donecker

CRAAdvanced Technical Development,

Technology Park,

Bentley, WA 6102, Australia

1. Murena, F. Famiglietti, V. \& Gioia, F. En. Prog. 12, 231
(1993).
2. Australian Patent Application PL6474 (1992).
3. Heinicke, G. Tribochemistry (Hanser, Munich, 1984).

\section{High jump}

SIR - Jha's note (Nature 365, 398; 1993) about timing devices in athletic events reminds me that two different philosophies are used in judging competitions. In the first category are running, throwing and long-jumping events, in which times or distances achieved are measured as exactly as possible by existing technology.

The second category comprises highjumping and pole-vaulting. Here the bar is either cleared or not, and its final height is measured exactly for the record. Although the winning jumper usually clears the bar with distance to spare, he/she receives no credit for that extra distance, other than anecdotally.

We could determine the actual height cleared for the record. We could raise a curtain of laser light along and above the bar shining from one verticle support to the other, and we could measure the height cleared by recording the brief attenuation of the light as the athlete's body or clothing passes through the beam. The bar would remain as a psychological aid to the jumper, and as the traditional means of determining the winner.

But high-jumping is an especially pure, simple and human contest, free of devices aiding the jump or determining the result. Perhaps we should just leave it that way.

James Johnson

Curams Kennels,

Westport,

Canada KOG 1 XO 